\title{
Microbiota conjuntival em pacientes com alergia ocular
}

\author{
Conjunctival microbiota in patients with ocular allergy
}

\author{
Alexandre Mattoso Libório ${ }^{1}$ \\ Maria Cristina Nishiwaki-Dantas ${ }^{2}$ \\ Lycia Mara Jenne Mimica ${ }^{3}$ \\ Paulo Elias Correa Dantas ${ }^{4}$ \\ Ana Luísa Höfling de Lima ${ }^{5}$
}

\section{RESUMO}

Objetivo: Avaliar a presença de microbiota aeróbia da conjuntiva de portadores de alergia ocular e comparar a um grupo controle. Métodos: Foram examinados 133 pacientes no período de abril a junho de 2001 divididos em 2 grupos. O grupo A foi composto de 63 portadores de conjuntivite alérgica (sem uso de medicação) e o grupo B de 70 pacientes do ambulatório geral (controle). Foram coletadas amostras do fundo de saco conjuntival do olho direito de todos os pacientes e o material foi semeado em meios sólidos de cultura (ágar sangue, chocolate e Sabouraud). Resultados: No grupo A, 30 culturas $(47,7 \%)$ foram positivas e no grupo B, $6(8,6 \%)$. Sete bactérias foram isoladas no grupo A e 4 no B. A análise estatística revelou associação significante entre a positividade dos cultivos e conjuntivite alérgica. Conclusão: Microbiota bacteriana foi mais freqüentemente encontrada nos pacientes com alergia ocular.

Descritores: Conjuntivite alérgica/diagnóstico; Conjuntiva/microbiologia; Ceratoconjuntivite; Contagem de colônia microbiana

\section{INTRODUÇÃO}

A microbiota da conjuntiva de olhos normais foi estabelecida no início do século $\mathrm{XIX}^{(1)}$. Foi comprovada a existência de bactérias aeróbias ou facultativas e questionada a presença de bactérias estritamente anaeróbias no saco conjuntival ${ }^{(2)}$. Os agentes mais comumente encontrados são o Staphylococcus epidermidis, Staphylococcus aureus, Corynebacterium spp e Propionibacterium acnes ${ }^{(3)}$.

Por outro lado, aproximadamente $20 \%$ da população geral tem alguma forma de alergia e uma significante parte apresenta manifestações oculares ${ }^{(4-5)}$.

A conjuntivite alérgica é uma alteração da conjuntiva caracterizada por reação de hipersensibilidade do tipo I e/ou $\operatorname{IV}^{(1-2)}$ e são classificadas em conjuntivite alérgica sazonal, conjuntivite alérgica perene, cérato-conjuntivite atópica, cérato-conjuntivite primaveril e conjuntivite papilar gigante ${ }^{(6-8)}$.

Nesta reação, ocorre liberação de células Th2, que estimulam a produção de imunoglobulinas $\mathrm{E}$ ( $\operatorname{IgE}$ ). As IgE, por sua vez, são ligadas às membranas de basófilos e mastócitos. Esta combinação leva à liberação de substâncias vasoativas e citotóxicas, que causam manifestações clínicas, como prurido intenso, lacrimejamento e fotofobia ${ }^{(5)}$.

Ao exame biomicroscópico, pode-se encontrar hiperemia conjuntival, hipertrofia papilar na conjuntiva palpebral e/ou límbica, quemose e, nos casos mais graves, como na ceratoconjuntivite primaveril e/ou atópica, envolvimento da córnea ${ }^{(5-6,8)}$.

A conjuntivite alérgica pode estar associada a condições infecciosas. Alguns trabalhos descrevem associação entre a ceratoconjuntivite primaveril e o tracoma, sugerindo o exame laboratorial através da imunofluores- 
cência direta para pesquisa de Chamydia trachomatis nos pacientes com alergia ocular ${ }^{(9-13)}$. As conjuntivites bacteriana e viral apresentam papilas, folículos, hiperemia conjuntival e secreção mucosa, que inicialmente podem mascarar ou sobrepor-se ao diagnóstico da conjuntivite alérgica ${ }^{(14)}$.

Ehlers, Donshik em 1992, descrevem a maior freqüência de ceratite infecciosa pelo vírus herpes simples em portadores de cérato-conjuntivite atópica ${ }^{(7)}$.

A alteração do estado imunológico da conjuntiva e o prurido, principal característica clínica da conjuntivite alérgica ${ }^{(4-5,15)}$, poderiam ser causa de um suposto aumento de agentes microbianos na conjuntiva.

\section{OBJETIVO}

O objetivo deste estudo foi avaliar a presença de microbiota aeróbica da conjuntiva de portadores de alergia ocular e compará-los a um grupo controle.

\section{MÉTODOS}

Foram examinados 133 pacientes no período de abril a julho de 2001, no Departamento de Oftalmologia da Santa Casa de São Paulo e da Universidade Federal de São Paulo, subdivididos em dois grupos:

\section{Grupo A}

Foram incluídos sessenta e três pacientes portadores de conjuntivite alérgica (conjuntivite alérgica sazonal e perene e ceratoconjuntivite atópica e primaveril), que não estivessem usando qualquer medicação.

Pacientes que usavam antibiótico tópico e/ou sistêmico não foram incluídos. As idades variaram entre 4 e 29 anos (média de $13,4$ e desvio padrão $\pm 7,1)$. Trinta e quatro pacientes $(53,9 \%)$ eram do sexo masculino e vinte e nove $(46,1 \%)$ do feminino.

\section{Grupo B (grupo controle)}

Setenta pacientes do Ambulatório Geral, que não apresentassem sinal e sintoma de qualquer forma de conjuntivite, que não usassem lente de contato ou antibiótico tópico e/ou sistêmico. As idades variaram entre 1 e 27 anos (média de 14,7 e desvio padrão $\pm 7,0)$. Trinta e cinco pacientes $(50,0 \%)$ eram do sexo masculino e trinta e cinco $(50,0 \%)$ do feminino.

Todos os pacientes do grupo A foram questionados quanto ao tempo de evolução da conjuntivite alérgica e sobre antecedentes pessoais e familiares de atopia sistêmica ou ocular.

\section{COLETA DE MATERIAL}

Foram colhidas amostras do fundo de saco conjuntival no olho direito de todos os pacientes estudados, sem instilação prévia de colírio anestésico, com auxílio de espátula de Kimu- ra. As amostras foram semeadas em meios sólidos de cultura de ágar sangue, chocolate e Sabouraud e também preparadas em lâminas para coloração de Gram e Giemsa.

As amostras semeadas foram imediatamente encaminhadas ao laboratório de Microbiologia da Faculdade de Ciências Médicas da Santa Casa de São Paulo e para o Laboratório de Doenças Externas Oculares da Universidade Federal de São Paulo, para análise.

No laboratório, as placas foram incubadas a $35^{\circ} \mathrm{C}$ durante 48 horas e, se houvesse crescimento bacteriano, era processada a identificação conforme método padronizado pela ASM (American Society for Microbiology) $)^{(15)}$.

\section{ANÁLISE ESTATÍSTICA}

Para análise dos resultados foram aplicados os seguintes testes:

1) Teste de Mann-Whitney (Siegel, 1988) para comparar as idades dos pacientes entre os grupos, a positividade em relação às idades dentro de cada grupo e entre eles ${ }^{(16)}$.

2) Teste do qui-quadrado (Siegel, 1988) com o objetivo de comparar os grupos A e B em relação às positividades da cultura $^{(16)}$. O mesmo teste foi aplicado para comparar, apenas no grupo alérgico, os sexos em relação à mesma positividade.

Fixou-se em 5\% $(\alpha \leq 0,05)$ o nível de rejeição da hipótese de nulidade. Os valores significantes foram assinalados com $\operatorname{asterisco}(*)$.

\section{RESULTADOS}

No grupo $\mathrm{A}$, foram encontrados 30 cultivos positivos $(47,7 \%)$ e no grupo B, $6(8,6 \%)$. O teste do qui-quadrado mostrou associação estatisticamente significante entre positividade dos cultivos e conjuntivite alérgica $\left(\mathrm{x}^{2}\right.$ calculado $=$ $25,61 * ; \mathrm{p}<0,001)$.

Foram isoladas 7 bactérias que estão apresentadas no quadro a seguir.

A idade dos pacientes do grupo A e B não diferiu signifi-

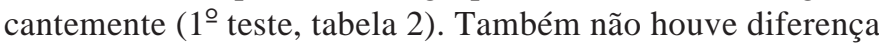
entre a idade dos positivos e negativos dentro de cada grupo $\left(2^{\circ}\right.$ teste, tabela 2$)$ e nem entre os grupos ( $3^{\circ}$ teste, tabela 2$)$.

\begin{tabular}{|c|c|c|}
\hline Agente & Grupo A & Grupo B \\
\hline Staphylococcus coagulase negativo & $21(31,3 \%)$ & $1(1,5 \%)$ \\
\hline Staphylococcus aureus & $8(12,0 \%)$ & $3(4,3 \%)$ \\
\hline Streptococcus viridans & $5(7,5 \%)$ & $1(1,5 \%)$ \\
\hline Streptococcus pneumoniae & $4(6,0 \%)$ & 0 \\
\hline Streptococcus alfa-hemolítico & $2(3,0 \%)$ & 0 \\
\hline Haemophilus spp & $1(1,5 \%)$ & 0 \\
\hline Bacilo gram + & $2(3,0 \%)$ & $2(3,0 \%)$ \\
\hline
\end{tabular}




\section{DISCUSSÃO}

Neste trabalho, foi marcante a presença de bactérias na conjuntiva de pacientes alérgicos, quando comparados ao grupo controle. Contudo não foi possível comparar nossa população de pacientes alérgicos com a literatura, devido a escassez de relatos sobre o assunto.

A análise laboratorial demonstrou maior positividade no grupo dos pacientes portadores de alergia ocular $(47,7 \%) \mathrm{em}$ relação ao grupo controle $(8,6 \%)$, sendo esses valores estatisticamente significantes $(\mathrm{p}<0,001)$, como visto na tabela 1 . Publicações anteriores mostraram maior percentual de cultivos

\begin{tabular}{|c|c|c|c|c|}
\hline \multicolumn{5}{|c|}{$\begin{array}{l}\text { Tabela 1. Resultados da análise do material colhido para cultivo, } \\
\text { dos portadores de conjuntivite alérgica (grupo A) e do grupo } \\
\text { controle (grupo B), atendidos no Departamento de Oftalmologia da } \\
\text { Santa Casa de São Paulo e da Universidade Federal de São Paulo, } \\
\text { no período de abril a julho de } 2001\end{array}$} \\
\hline Grupos & $\begin{array}{l}\text { Cultivo } \\
\text { positivo }\end{array}$ & $\begin{array}{c}\text { Cultivo } \\
\text { negativo }\end{array}$ & Total & $\begin{array}{c}\% \text { de } \\
\text { positivo }\end{array}$ \\
\hline Grupo A & 30 & 33 & 63 & 47,7 \\
\hline Grupo B & 6 & 64 & 70 & 8,6 \\
\hline Total & 36 & 97 & 133 & 27,1 \\
\hline
\end{tabular}

positivos na população não alérgica ${ }^{(17-18)}$. No entanto, esses estudos foram realizados utilizando meio líquido de cultura para pesquisa de bactérias anaeróbicas, enquanto que em nossa pesquisa utilizamos meios sólidos de cultura para isolamento somente de bactérias aeróbicas.

A análise estatística não mostrou diferença significante entre os grupos com relação às idades, nem quanto à positividade $\mathrm{e}$ negatividade das culturas dentro de cada grupo e entre eles.

Neste estudo ficou evidente a presença de bactérias da microbiota normal nos grupos estudados, porém o número de unidades formadoras de colônias de cada espécie identificada tinham concentração maior no grupo de pacientes alérgicos.

A presença de maior número de pacientes com crescimento positivo das amostras conjuntivais nos pacientes alérgicos pode provavelmente ser explicada pela maior manipulação dos olhos provocada pelo ato de coçar, que deve transportar bactérias do meio externo e anexos oculares para o saco conjuntival.

Outra possível explicação para a maior presença de bactérias nos pacientes alérgicos poderia ser explicada pelas alterações da superfície ocular e aumento da secreção, que facilitariam a coleta de material para análise. Nos olhos do grupo controle, por outro lado, a escassez de material dificultou a coleta.

Observando os resultados de nossa pesquisa, sugerimos

\begin{tabular}{|c|c|c|c|c|c|c|c|c|}
\hline & \multicolumn{4}{|c|}{ Grupo A } & \multicolumn{4}{|c|}{ Grupo B } \\
\hline & \multicolumn{2}{|c|}{ Positivo } & \multicolumn{2}{|c|}{ Negativo } & \multirow{2}{*}{$\begin{array}{c}\text { Positivo } \\
10\end{array}$} & \multicolumn{3}{|c|}{ Negativo } \\
\hline & 16 & 12 & 21 & 14 & & 13 & 17 & 4 \\
\hline & 5 & 4 & 7 & 9 & 15 & 25 & 21 & 5 \\
\hline & 15 & 12 & 9 & 5 & 19 & 27 & 18 & 9 \\
\hline & 10 & 16 & 5 & 11 & 27 & 25 & 23 & 13 \\
\hline & 9 & 12 & 15 & 8 & 6 & 27 & 24 & 7 \\
\hline & 8 & 21 & 15 & 15 & 8 & 24 & 23 & 7 \\
\hline & 5 & 27 & 24 & 8 & & 19 & 14 & 1 \\
\hline & 11 & 20 & 5 & 7 & & 11 & 26 & 8 \\
\hline & 7 & 28 & 7 & 18 & & 22 & 22 & 7 \\
\hline & 13 & 18 & 10 & 11 & & 18 & 24 & 6 \\
\hline & 6 & 26 & 8 & 28 & & 17 & 5 & 6 \\
\hline & 16 & 5 & 7 & 25 & & 15 & 5 & 9 \\
\hline & 8 & 25 & 7 & 27 & & 13 & 14 & 14 \\
\hline & 5 & 28 & 11 & & & 16 & 16 & 7 \\
\hline \multirow{8}{*}{\multicolumn{2}{|c|}{9}} & 29 & 12 & & & 18 & 9 & 12 \\
\hline & & & & & & 26 & 10 & 14 \\
\hline & & & & & & 15 & 12 & 10 \\
\hline & & & & & & 19 & 12 & 6 \\
\hline & & & & & & 22 & 10 & 6 \\
\hline & & & & & & 27 & 7 & 10 \\
\hline & & & & & & 20 & 16 & \\
\hline & & & & & & 23 & 7 & \\
\hline Média & \multicolumn{2}{|c|}{14,2} & \multicolumn{2}{|c|}{12,8} & 14,2 & & 15,0 & \\
\hline \multicolumn{9}{|c|}{ 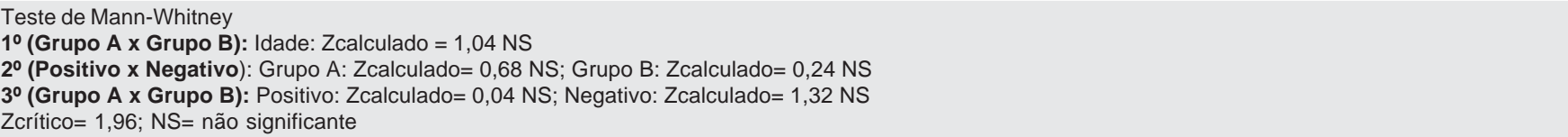 } \\
\hline
\end{tabular}


maior cuidado na realização de procedimentos invasivos nos olhos de pacientes alérgicos, tendo em vista a população bacteriana aumentada nesses olhos em relação a olhos não alérgicos.

\section{CONCLUSÃO}

Microbiota bacteriana foi mais freqüentemente encontrada nos pacientes com alergia ocular.

\section{ABSTRACT}

Purpose: To evaluate de presence of conjunctival aerobic microbiota in patients with ocular allergy as compared to a control group. Methods: One hundred and thirty-three patients were evaluated from April to June 2001 and divided into 2 groups. Sixty-three patients with allergic conjunctivitis (without medication) were in group A and 70 patients from the general outpatient clinic were in group B (control group). Samples from the conjunctival sac of the right eye were collected and cultured in solid media (blood, chocolate and Sabouraud agar). Results: In group A, 30 cultures $(47.7 \%)$ were positive and $6(8.6 \%)$ in group B. Seven bacteria were isolated from group A and 4 from group B. Statistical analysis revealed significant association between positive cultures and allergic conjunctivitis. Conclusion: Bacterial microbiota was more frequently found in patients with ocular allergy.

Keywords: Conjunctivis, allergic/diagnosis; Conjunctiva/microbiology; Keratoconjunctivitis; Colony count, microbial

\section{REFERÊNCIAS}

1. Lawson A. The bacteriology of the normal conjunctival sac and its practical bearing on the utility of antiseptics in ophthalmic surgery. Br Med J. 1898;2:486-7.
2. Campos MSQ, Sato EH, Nose W, Mos EN, Santos MAA. Microbiota anaeróbica do saco conjuntival humano normal. Arq Bras Oftalmol. 1989;52(6):193-5.

3. Souza LB, Lima ALH. Flora ocular normal. In: Lima ALH, Nishiwaki-Dantas MC, Alves MR. Manual do CBO: doenças externas oculares e córnea. Rio de Janeiro: Cultura Médica; 1999. p.114-3.

4. Holzchuh N, Kara-José N, Alves MR. Alergia. In: Belfort R Jr, Kara-José N. Córnea clínica- cirúrgica; São Paulo: Roca; 1996. p.251.

5. Nishiwaki-Dantas MC. Desordens imunológicas da conjuntiva. In: Lima ALH, Nishiwaki-Dantas MC, Alves MR. Manual do CBO: doenças externas oculares e córnea. Rio de Janeiro: Cultura Médica; 1999. p.210-4.

6. Abelson MB, George MA, Garofalo C. Differential diagnosis of ocular allergic disorders. Ann Allergy. 1993;70(2):95-109. Erratum in: Ann Allergy. 1993; $70(3): 192$.

7. Ehlers WH, Donshik PC. Allergic ocular disorders: a spectrum of diseases. CLAO J. 1992;18(2):117-24.

8. Foster CS. The pathophysiology of ocular allergy: current thinking. Allergy. 1995;50(21 Suppl.):6-9; discussion 34-8.

9. Friedlaender $\mathrm{MH}$, Cameron J. Vernal keratoconjunctivitis and trachoma. Int Ophthalmol. 1988;12(1):47-51.

10. Melo CM, Nishiwaki-Dantas MC, Dantas PEC, Guiduli T, Finzi S. Imunofluorescência direta para pesquisa de Chamydia trachomatis em portadores de conjuntivite alérgica. In: 14 Congresso Brasileiro de Prevenção à Cegueira; Natal, 2000.

11. Rao SK, Madhavan HN, Padmanabhan P, Lakshmi GS, Natarajan K, Garg D. Ocular chlamydial infections. Clinicomicrobiological correlations. Cornea. 1996;15(1):62-5.

12. Romero IL, Belfort Neto R, Nishiwaki-Dantas MC, Cohen R, Finzi S, BravoOsório LM. Reação em cadeia de polimerase para pesquisa de Chamydia trachomatis nos pacientes portadores de conjuntivite alérgica crônica. In: VIII Forúm de Pesquisa - Fundação Arnaldo Vieira de Carvalho - Faculdade de Ciência Médica da Santa Casa de Misericórdia de São Paulo; São Paulo, 2000.

13. Vérin P, Gendre P, Aouizerate F, Gauthier L. Fréquence de la présence des chamydiae chez les porteurs de conjunctive printaniere. Rev Int Trach Pathol Ocul Trop Subtrop Sante Publique. 1989;66(3-4):111-8.

14. Faria F. Lesões elementares da conjuntiva. In: Faria F. Manual de biomicroscopia da conjuntiva. São Paulo: Editora Santos; 1989. p.85.

15. Scarpi MJ, Silva RJM, Ferreira IA, Barbosa FAC, Plut RCA. Prevalência de tracoma do município de Palmares, Estado de Pernambuco, Brasil. Arq Bras Oftalmol. 1990;53(4):171-5.

16. Siegel S, Castellan Jr NJ. Non parametric studies. $2^{\text {nd }}$ ed. New York: Mc Graw Hill; 1988. 399p.

17. Khorazo D, Thompson R. Conjunctival anaerobic and aerobic bacterial flora in paediatric versus CE. Am J Ophthalmol. 1935;18:1114-6.

18. Singer TR, Isenberg SJ, Apt L. Conjunctival anaerobic and aerobic bacterial flora in paediatric versus adult subjects. Br J Ophthalmol. 1988;72(6):448-51. 